\title{
Diversification When It Hurts? \\ The Joint Distributions of Real Estate and Equity Markets
}

\author{
John Knight \\ Department of Economics, \\ University of Western Ontario, \\ London, Ontario, Canada N6A 5C2 \\ Colin Lizieri ${ }^{1}$ \\ Department of Real Estate \& Planning \\ University of Reading Business School, \\ Whiteknights, Reading, RG6 6AW UK \\ Stephen Satchell \\ Faculty of Economics \& Politics, \\ University of Cambridge, \\ Austin Robinson Building, Cambridge, UK CB3 9DD \\ Paper Presented to the \\ European Real Estate Society Annual Conference \\ Dublin, June 2005 \\ *** please contact authors for latest version $* * *$
}

\footnotetext{
${ }^{1}$ Contact author: c.m.lizieri@rdg.ac.uk, +44 (0)118 3786339
} 


\section{Diversification When It Hurts? The Joint Distributions of Real Estate and Equity Markets}

Key Words: Copula, Portfolio Diversification, Tail Dependence, Real Estate

\section{Introduction}

In constructing mixed asset portfolios, it is often argued that commercial real estate exhibits behaviour that creates strong diversification gains. However, the theoretical allocations to real estate are not matched by observed investor behaviour. This has been attributed to unfavourable characteristics of real estate as an asset - large lot size, high transaction costs, illiquidity and information asymmetry. To some extent, these disadvantages can be overcome through investment in real estate securities in public markets ${ }^{2}$. Do such real estate securities provide diversification benefits? If so, are those benefits consistent over time or does diversification disappear when it is most needed - when one asset class is providing low or negative returns? In this paper, we seek to examine the relationship between commercial real estate stocks and the general equity market in the tails of their respective return distributions.

\section{Real Estate Returns and the Stock Market}

In investigating the diversification benefits of real estate, early research frequently found segmentation between real estate and equities (see, for example, Liu et al., 1990). However, such findings typically rely on valuation or appraisal based returns series. By contrast, when public real estate stocks are considered, there appear to be close links between the two asset types (see, for example, Ling \& Naranjo, 1999, Gyourko \& Keim 1992). While some have argued that the return distributions of real estate stocks are not representative of the underlying market and that the reported direct market returns are representative, the balance of research argues that the low volatility, high serial correlation and low or negative covariance with other asset classes in appraisal indices is largely a measurement issue.

\footnotetext{
${ }^{2}$ or, for professional investors, by investing in securitised or unitised property vehicles in the private market.
} 
One common explanation of the behaviour of appraisal-based indices is that they are "smoothed" due to valuer behaviour (see Geltner et al., 2003, for a review). Valuers adjust prior appraisals using a form of Bayesian updating as new information arrives. As a result volatility in the observed series is damped and serial correlation induced. This has led to a number of methods that aim to extract the underlying pricing signals, notably in the work of Geltner (1993; Geltner \& Barkham, 1995, Fisher et al. 2003), where the price signal is extracted from a capital valuation series using a desmoothing parameter $P_{t}=\left(V_{t}-\alpha V_{t-1}\right) /(1-\alpha)$. To an extent, the decision on the value of the $\alpha$ is somewhat ad hoc, with a value chosen to create a particular level of volatility ("half the volatility of common stocks") or to reduce serial correlation to a desired level. Others have used statistical means to extract a price signal - Fu (2003), for example using a Kalman filter approach to recover a "true" price series which exhibits greater variance, weaker autocorrelation and a closer correlation to REIT stocks.

Lai and Wang (1998) argue that smoothing at individual property level could increase volatility. This may be true, but, at least at the aggregate level, the balance of evidence suggests a reduction. Clayton et al. (2001) provide empirical evidence of appraisal smoothing while Brown \& Matysiak (2000) set out an alternative explanation of smoothing based on sticky valuations, cross-serial correlation and aggregation effects. Further reason for casting doubt on the validity of appraisal-based indices as a measure of market performance comes from the problems facing an individual investor holding real estate directly. Not only is there a large lot size problem (which, allied to heterogeneity, makes it difficult to track the aggregate index), there are significant issues associated with liquidity. The length of time taken to sell an asset and the additional pricing uncertainty this induces means that the (unrealised) valuation based indices understate the ex ante risk faced by an investor (Bond \& Hwang, 2004; Fisher et al. 2003).

Given the difficulties presented by investing in real estate in private markets, it might be thought that real estate equities would be an appropriate substitute, providing divisibility, relative liquidity, lower transaction costs and a benchmark based on transaction prices. 
However, real estate equity behaviour does not fully accord with expectations about property performance. Firms frequently trade at a discount to net asset value. NAV discount is a particular issue in the UK where property companies are taxable entities, creating a tax drain, but appears in certain periods in markets where there are taxneutral REIT structures. Barkham and Ward (1999) explain the discount in terms of volatility from gearing and from noise traders influence. Nonetheless, they find a long-run relationship between property company performance and the direct market: "property shares, in the long-run are linked to the value of the underlying assets". With the UK moving towards a REIT structure and with growing retail interest in investment in commercial real estate as a portfolio diversifier, it seems relevant to examine the relationship between real estate stocks and the general equity market.

\section{Return Distributions and Asymmetric Dependence}

Examination of the return distributions of real estate indices suggests non-normality in both public and private markets (see e.g. Young \& Graff, 1995; for a review, see Lizieri \& Ward, 2001). Distributions are found, typically, to be peaked and fat-tailed. Public market, traded estate securities tend to have similar properties to other equities. There is some evidence of non-linearity (Lizieri et al. 1998, Maitland-Smith \& Brooks, 1999, Okunev \& Wilson, 1997). These characteristics of asset behaviour have led to suggestions that portfolio allocation models including real estate should use a risk measure other than the variance. Thus Byrne \& Lee (1997) propose use of a mean absolute deviation risk measure, Hamelink \& Hoesli (2004) use a maximum drawdown function and others have suggested a semi-variance measure (for example Bond \& Patel, 2003). The literature, however, has not considered explicitly whether diversification benefits are uniform across the distribution ${ }^{3}$.

By contrast, recent empirical finance literature has reported that stocks exhibit some form of asymmetric dependence (see, for example: Ang \& Chen, 2002; Ang \& Bekaert, 2002; Bae, Karolyi \& Stulz, 2003; Campbell et al., 2002; Hartmann et al. 2004; Longin \& Solnik, 2001). Such research, using a variety of techniques, including

\footnotetext{
${ }^{3}$ However, Lu \& Mei (1999) observe that international real estate stocks show a higher correlation with US stocks when US markets are performing badly, implying diversification gains are least when investors need them most.
} 
dynamic conditional correlation analysis, non-parametric tail dependence measures and the copula approach employed in this paper, examines dependence relating to extreme events, or the tails of the distributions in equity, currency and bond markets and explores contagion effects in market "crises". There are significant implications if the dependence behaviour for extreme realisations differs from the aggregate dependence behaviour: specifically, use of the standard Pearson correlation coefficient may result in misallocation and expose investors to high levels of risk.

The remainder of this paper focuses on tail dependence and the linkages between real estate stocks and equity markets during extreme events. We begin by defining tail dependence and describe the copula approach to be adopted. Next we introduce our data and model dependence across pairs of real estate and equity variables. Finally, we set out some conclusions and implications of the findings.

\section{Tail Dependence: Methods And Estimation}

\section{Tail Correlations and the Copula Function}

Suppose we have a pair of random variables $\left(\mathrm{X}_{t}, \mathrm{Y}_{\mathrm{t}}\right)$ with a joint cumulative distribution function $\mathrm{F}_{\mathrm{XY}}(\mathrm{x}, \mathrm{y})$ and with marginal distribution functions $\mathrm{F}_{\mathrm{X}}(\mathrm{x})$ and $F_{Y}(y)$, then the copula $C($, $)$ is defined by $F_{X Y}(x, y)=C\left(F_{X}(x), F_{Y}(y)\right)$. If we transform $\mathrm{u}=\mathrm{F}_{\mathrm{X}}(\mathrm{x}), \mathrm{v}=\mathrm{F}_{\mathrm{y}}(\mathrm{y})$ we have a function $\mathrm{C}(\mathrm{u}, \mathrm{v})$ defined on a unit rectangle, $0 \leq \mathrm{u} \leq 1,0 \leq \mathrm{v} \leq 1$, where both $\mathrm{u}$ and $\mathrm{v}$ are uniformly distributed. Technically, $\mathrm{C}(\mathrm{u}, \mathrm{v})$ represents a bivariate and possible correlated distribution function with uniform marginals. An important special case is the independence copula, $\mathrm{C}(\mathrm{u}, \mathrm{v})=\mathrm{uv}$.

\section{Marginal Distributions}

In keeping with the financial econometrics literature, and following Patton (2005), we assume that the marginal distributions of our index returns are AR(1) processes with $\operatorname{GARCH}(1,1)$ volatility and $\mathrm{t}$ distributed residuals. This is fairly general and nests a number of common special cases including normality. It also allows for conditional (time-varying) marginal behaviour. However, we do not allow time-varying copula behaviour, because of the difficulty of identifying the relevant parameters and the unavailability of plausible specifications. 
The basic model is

$$
\begin{aligned}
& X_{t}=\eta_{X}+\phi_{x} X_{t-1}+\varepsilon_{t} \\
& \sigma_{x, t}^{2}=\omega_{x}+\beta_{x} \sigma_{x, t-1}^{2}+\alpha_{x} \varepsilon_{t-1}^{2}
\end{aligned}
$$

and $\sqrt{\frac{\mathrm{v}_{\mathrm{x}}}{\sigma_{\mathrm{x}, \mathrm{t}}^{2}\left(\mathrm{v}_{\mathrm{x}}-2\right)}}: \varepsilon_{\mathrm{t}}$ is assumed distributed as a standardised $\mathrm{t}_{\mathrm{vx}}$.

There is a parallel specification for $Y_{t}$ which is identical except that all parameters are subscripted y. We allow the possibility of $\operatorname{GARCH}(p, q)$ in what follows.

\section{The Empirical Copula Matrix}

To investigate the behaviour of the copulae prior to detailed analysis, we consider a simple treatment of the data for $\mathrm{C}($,) some arbitrary copula. We purge the data of the marginals based on our representation given by (...). This is equivalent to estimating equations (1) and (2), taking our standardised residuals and then computing ( $\mathrm{u}_{\mathrm{t}}$ and $\left.v_{t}\right), t=1, \ldots, n$, where $u_{t}$ and $v_{t}$ are both determined from their corresponding student $t$ distribution functions. These will be uniformly distributed marginally but with an unknown copula which we wish to determined.

We next define our empirical copula matrix. Let us consider a general case where we have $\mathrm{k}$ different classes and we define $\mathrm{n}_{\mathrm{i}, \mathrm{j}}$ as follows:

$$
\begin{aligned}
& n_{i, j, t}=1 \text { if } r_{i-1} \leq U_{t} \leq r_{i} \text { and } r_{j-1} \leq V_{t} \leq r_{j} \\
& =0 \text { otherwise. }
\end{aligned}
$$

$\mathrm{n}_{\mathrm{i}, \mathrm{j}, \mathrm{t}}$ is thus a binary variable that takes the value one in a rectangle in $\left(\mathrm{U}_{t}, \mathrm{~V}_{t}\right)$ space and is zero otherwise. Summing $n_{i, j, t}$ over $t$ for $i, j=1, \ldots, k$ and $t=1, \ldots, n$ we can form an $(\mathrm{k} \times \mathrm{k})$ matrix. From these we can easily get:

$$
B_{i, j}=\text { the number of times } r_{i-1} \leq U_{t}<r_{i} \text { and } r_{j-1} \leq V_{t}<r_{j}
$$

where $B_{i, j}=\sum_{t=1}^{n} n_{i, j, t}, \quad i=1, \ldots, k$ and $j=1, \ldots, k$.

Then sorting the observations of both $\mathrm{x}_{\mathrm{t}}$ and $\mathrm{y}_{\mathrm{t}}$ from the minimum to the maximum value, we note that the expected number of entries in each cell is equal to

$$
\begin{array}{r}
C\left(r_{i}, r_{j}\right)+C\left(r_{i-1}, r_{j-1}\right) \\
-C\left(r_{i}, r_{j-1}\right)+C\left(r_{i-1}, r_{j}\right)
\end{array}
$$

for any copula (,). 
In the case that it is the independence copula, $C\left(r_{i}, r_{j}\right)=r_{i} r_{j}$, and the expression simplifies to $\left(r_{i}-r_{i-1}\right)\left(r_{j}-r_{j-1}\right)$. We set $k$ equal to 10 , so that our copula is counted over 100 rectangles, $\mathrm{n}=216$ so that, for independence, we expect 2.16 entries per cell.

The Empirical Copula Matrix provides a valuable visualisation of any tail dependence between the two series. This can be seen as an extension of the empirical copula as defined by Deheuvels $(1979,1981)$. Deheuvels $(1978,1981)$ proves that the empirical copula converges uniformly to the underlying copula. It follows immediately from this that the empirical copula matrix will converge uniformly to the underlying copula matrix. What makes this especially useful is that it can be computed with respect to the original returns: we do not need to transform the data as in equations (1) and (2). If we did so, we would get exactly the same cell frequencies.

\section{Data and Empirical Results}

Our data are monthly index number series, from December 1986 to December 2004. The start date here is governed by the availability of direct, private real estate indices at monthly frequency. For the United Kingdom, we use the Investment Property Databank total returns monthly series. While this does not suffer from the "stale appraisal" problem of the equivalent US NCREIF data, it is generally assumed to be subject to valuation smoothing. To counter this, we desmooth the capital growth series using the standard Geltner framework described above ${ }^{4}$, with alpha set to produce a variance ...., then recombine the income returns to produce a desmoothed total return series. The UK equity market series is the FT All Share index, the broadest UK equity series; as a measure of the public property market, we use the FT Real Estate sector index. Real estate represents around 2\% of the market capitalisation of UK equities. For global equities, we employ the Morgan Stanley Capital International World Equity series; this is compared to the GPR World Real Estate stocks index, purged of open-ended companies ${ }^{5}$. Both the global series are US\$ denominated.

\footnotetext{
${ }^{4}$ Other desmoothing models produced very similar results.

${ }^{5}$ GPR is preferred to EPRA for the time-series and the availability of pure closed-end data series.
} 
Figure 1 sets out descriptive statistics for the log differences of the index number series. It is readily apparent that the direct market real estate distributions are very different to the equity indices. The standard deviation of returns is substantially below that of the various equity market series (the smoothed UK series has an annualised standard deviation of around $2.7 \%$ compared to around $21 \%$ for the equivalent UK property company series: such a lack of volatility is scarcely credible). The first and second order serial correlation statistics emphasise the smoothed nature of the valuation based series (for a discussion of the valuation processes associated with the IPD monthly series see McAllister et al., 2003). The desmoothed IPD series reduces the serial correlation problem and introduces some additional volatility. The FT Real Estate series does exhibit some first order serial correlation. The equity series are all characterised by fat tails and negative skewness. As is standard in these analyses, the equity market series exhibit high contemporaneous correlation, while the IPD series have near zero correlations with all series except each other.

Figure 1: Return Series: Descriptive Statistics and Correlations

\begin{tabular}{|l|c|c|c|c|c|c|}
\hline & IPDTot & IPDDes & FTRes & GPRGlob & FTAS & MSWorld \\
\hline Mean & 0.0086 & 0.0087 & 0.0076 & 0.0068 & 0.0080 & 0.0072 \\
\hline Standard Dev. & 0.0077 & 0.0129 & 0.0606 & 0.0489 & 0.0487 & 0.0438 \\
\hline Kurtosis & 4.122 & 7.510 & 9.184 & 4.172 & 10.515 & 4.795 \\
\hline Skewness & 0.265 & 0.116 & -1.399 & -0.288 & -1.510 & -0.774 \\
\hline Jarque Bera & 13.83 & 183.52 & 413.74 & 15.32 & 590.37 & 50.263 \\
\hline $1^{\text {st }}$ Order Serial & 0.882 & 0.108 & 0.165 & 0.071 & 0.080 & 0.029 \\
\hline $2^{\text {nd }}$ Order Serial & 0.844 & 0.283 & -0.020 & 0.062 & -0.112 & -0.074 \\
\hline
\end{tabular}

\begin{tabular}{|l|c|c|c|c|c|c|c|}
\hline & IPDTot & IPDDes & FTRes & FTAS & GPRGlob & MSWorld & MedGilt \\
\hline IPDTot & 1.000 & & & & & & \\
\hline IPDDes & 0.766 & 1.000 & & & & & \\
\hline FTRes & 0.012 & -0.010 & 1.000 & & & & \\
\hline FTAS & -0.059 & -0.054 & 0.730 & 1.000 & & & \\
\hline GPRGlob & 0.041 & -0.028 & 0.531 & 0.478 & 1.000 & & \\
\hline MSWorld & 0.008 & -0.064 & 0.499 & 0.739 & 0.731 & 1.000 & \\
\hline
\end{tabular}

Full details of the empirical estimation of the marginal distributions for the four equity series are shown in Appendix A. Each has a different characteristic form. The FT All Share is best modelled as $\operatorname{GARCH}(2,4)$-t ; the FT Real Estate series as AR(1)GARCH(1,2) picking up the serial correlation observed above; the MS World Equity series $\operatorname{GARCH}(0,2)$-t and the GPR World real estate series as $\operatorname{GARCH}(1,1)$. The two IPD series cannot be modelled effectively within this framework. 
Figure 2 sets out empirical copulae matrices (based on equations (3) and (4)) comparing pairs of series each consisting of the logged differences from the real estate series with the equivalent equity market logged differences. Inspection of Panels A and B, Figure 2 suggest that the IPD returns (smoothed or desmoothed) contain virtually no useful bivariate information and are independent of the Stock Market returns. This is tested in the usual way by adapting independence tests for two-way contingency tables. While this might be taken as an indicator that direct real estate brings strong diversification benefits, it seems more likely that this is a measurement issue with the volatility misstated in the appraisal based returns. We return to this in the concluding section.

By contrast, the large numbers in the top and bottom corners of the FT All Share versus the FT Real Estate Sector and the GPR Global Property returns versus MS World Equity returns show clear evidence of upper and lower tail dependence which we shall endeavour to estimate.

In our copula analysis we analyse a copula used by Patton (2005). This is a symmetrised version of a copula originally described in Joe (1997). Using the notation of Patton (page 14, equations 13 and 14), the Joe-Clayton copula is shown as

$$
\begin{aligned}
\mathrm{C}_{\mathrm{JC}}\left(\mathrm{u}, \mathrm{v} \mid \tau^{\mathrm{U}}, \tau^{\mathrm{L}}\right) & =1-\left(1-\left\{\left[1-(1-\mathrm{u})^{\mathrm{k}}\right]^{-\gamma}+\left[1-(1-\mathrm{v})^{\mathrm{k}}\right]^{-\gamma}-1\right\}^{-1 / \gamma}\right)^{1 / \mathrm{k}} \\
\text { where } \mathrm{k} & =1 / \log _{2}\left(2-\tau^{\mathrm{U}}\right) \\
\gamma & =-1 / \log _{2}\left(\tau^{\mathrm{L}}\right) \\
\text { and } \tau^{\mathrm{U}} & \in(0,1), \tau^{\mathrm{L}} \in(0,1)
\end{aligned}
$$


Figure 2 Empirical Copulae Matrices, Log Differenced Returns

Panel A FT All Share and IPD Desmoothed Returns

\begin{tabular}{|l|l|l|l|l|l|l|l|l|l|}
\hline $\mathbf{3 . 0 0}$ & $\mathbf{2 . 0 0}$ & 4.00 & 2.00 & 2.00 & 2.00 & 2.00 & 1.00 & 1.00 & 2.00 \\
\hline $\mathbf{2 . 0 0}$ & $\mathbf{3 . 0 0}$ & 3.00 & 3.00 & 4.00 & 0.00 & 2.00 & 1.00 & 1.00 & 2.00 \\
\hline 3.00 & 1.00 & 1.00 & 4.00 & 2.00 & 1.00 & 1.00 & 1.00 & 5.00 & 2.00 \\
\hline 0.00 & 3.00 & 2.00 & 3.00 & 1.00 & 2.00 & 2.00 & 4.00 & 0.00 & 5.00 \\
\hline 4.00 & 0.00 & 2.00 & 2.00 & 3.00 & 3.00 & 5.00 & 1.00 & 2.00 & 0.00 \\
\hline 1.00 & 2.00 & 2.00 & 1.00 & 2.00 & 3.00 & 4.00 & 2.00 & 3.00 & 2.00 \\
\hline 0.00 & 1.00 & 1.00 & 1.00 & 4.00 & 3.00 & 1.00 & 5.00 & 3.00 & 3.00 \\
\hline 3.00 & 5.00 & 1.00 & 3.00 & 0.00 & 4.00 & 1.00 & 0.00 & 2.00 & 2.00 \\
\hline 0.00 & 4.00 & 2.00 & 0.00 & 3.00 & 2.00 & 2.00 & 3.00 & $\mathbf{2 . 0 0}$ & $\mathbf{3 . 0 0}$ \\
\hline 5.00 & 0.00 & 3.00 & 3.00 & 1.00 & 2.00 & 2.00 & 3.00 & $\mathbf{2 . 0 0}$ & $\mathbf{2 . 0 0}$ \\
\hline
\end{tabular}

$\chi^{2}=80.30, p(\chi)=0.50$

Panel B: FT All Share and IPD Total Return Smoothed

\begin{tabular}{|l|l|l|l|l|l|l|l|l|l|}
\hline $\mathbf{4 . 0 0}$ & $\mathbf{1 . 0 0}$ & 3.00 & 1.00 & 0.00 & 6.00 & 2.00 & 0.00 & 2.00 & 2.00 \\
\hline $\mathbf{3 . 0 0}$ & $\mathbf{2 . 0 0}$ & 1.00 & 4.00 & 2.00 & 1.00 & 1.00 & 4.00 & 0.00 & 3.00 \\
\hline 1.00 & 1.00 & 3.00 & 4.00 & 1.00 & 3.00 & 1.00 & 2.00 & 5.00 & 0.00 \\
\hline 1.00 & 3.00 & 3.00 & 1.00 & 2.00 & 0.00 & 4.00 & 2.00 & 2.00 & 4.00 \\
\hline 2.00 & 4.00 & 0.00 & 2.00 & 2.00 & 5.00 & 2.00 & 3.00 & 0.00 & 2.00 \\
\hline 2.00 & 0.00 & 5.00 & 1.00 & 6.00 & 0.00 & 2.00 & 2.00 & 2.00 & 2.00 \\
\hline 0.00 & 3.00 & 2.00 & 2.00 & 1.00 & 2.00 & 2.00 & 4.00 & 4.00 & 2.00 \\
\hline 4.00 & 2.00 & 2.00 & 3.00 & 2.00 & 2.00 & 1.00 & 0.00 & 2.00 & 3.00 \\
\hline 0.00 & 3.00 & 1.00 & 1.00 & 4.00 & 2.00 & 4.00 & 2.00 & $\mathbf{2 . 0 0}$ & $\mathbf{2 . 0 0}$ \\
\hline 4.00 & 2.00 & 1.00 & 3.00 & 2.00 & 1.00 & 3.00 & 2.00 & $\mathbf{3 . 0 0}$ & $\mathbf{2 . 0 0}$ \\
\hline
\end{tabular}

Panel C FT All Share versus FT Real Estate Returns

\begin{tabular}{|c|c|c|c|c|c|c|c|c|c|}
\hline $\mathbf{1 4 . 0 0}$ & $\mathbf{4 . 0 0}$ & 0.00 & 2.00 & 0.00 & 0.00 & 1.00 & 0.00 & 0.00 & 0.00 \\
\hline $\mathbf{2 . 0 0}$ & $\mathbf{7 . 0 0}$ & 5.00 & 0.00 & 2.00 & 1.00 & 2.00 & 1.00 & 1.00 & 0.00 \\
\hline 1.00 & 1.00 & 5.00 & 4.00 & 2.00 & 5.00 & 0.00 & 2.00 & 1.00 & 0.00 \\
\hline 3.00 & 3.00 & 4.00 & 3.00 & 3.00 & 2.00 & 1.00 & 1.00 & 2.00 & 0.00 \\
\hline 1.00 & 2.00 & 1.00 & 3.00 & 6.00 & 3.00 & 3.00 & 1.00 & 2.00 & 0.00 \\
\hline 0.00 & 2.00 & 3.00 & 1.00 & 4.00 & 4.00 & 0.00 & 4.00 & 1.00 & 3.00 \\
\hline 0.00 & 1.00 & 1.00 & 1.00 & 3.00 & 3.00 & 4.00 & 3.00 & 2.00 & 4.00 \\
\hline 0.00 & 0.00 & 0.00 & 4.00 & 2.00 & 1.00 & 4.00 & 3.00 & 3.00 & 4.00 \\
\hline 0.00 & 0.00 & 2.00 & 4.00 & 0.00 & 0.00 & 4.00 & 2.00 & 3.00 & $\mathbf{6 . 0 0}$ \\
\hline 0.00 & 1.00 & 0.00 & 0.00 & 0.00 & 3.00 & 3.00 & 4.00 & $\mathbf{7 . 0 0}$ & 5.00 \\
\hline
\end{tabular}

$\chi^{2}=214.45, \mathrm{p}(\chi)=0.000$

Panel D GPR Global Property against MS World Equity

\begin{tabular}{|c|c|c|c|c|c|c|c|c|c|}
\hline $\mathbf{1 0 . 0 0}$ & $\mathbf{5 . 0 0}$ & 0.00 & 0.00 & 4.00 & 1.00 & 0.00 & 1.00 & 0.00 & 0.00 \\
\hline $\mathbf{4 . 0 0}$ & $\mathbf{3 . 0 0}$ & 3.00 & 4.00 & 2.00 & 2.00 & 1.00 & 2.00 & 0.00 & 0.00 \\
\hline 4.00 & 4.00 & 6.00 & 3.00 & 3.00 & 0.00 & 1.00 & 0.00 & 0.00 & 0.00 \\
\hline 3.00 & 5.00 & 3.00 & 5.00 & 2.00 & 1.00 & 1.00 & 2.00 & 0.00 & 0.00 \\
\hline 0.00 & 3.00 & 2.00 & 1.00 & 4.00 & 6.00 & 2.00 & 2.00 & 2.00 & 0.00 \\
\hline 0.00 & 0.00 & 2.00 & 5.00 & 1.00 & 4.00 & 5.00 & 1.00 & 3.00 & 1.00 \\
\hline 0.00 & 1.00 & 3.00 & 0.00 & 3.00 & 2.00 & 3.00 & 4.00 & 4.00 & 2.00 \\
\hline 0.00 & 0.00 & 0.00 & 3.00 & 1.00 & 4.00 & 3.00 & 4.00 & 2.00 & 4.00 \\
\hline 0.00 & 0.00 & 2.00 & 0.00 & 2.00 & 2.00 & 2.00 & 2.00 & $\mathbf{7 . 0 0}$ & 5.00 \\
\hline 0.00 & 0.00 & 0.00 & 1.00 & 0.00 & 0.00 & 4.00 & 3.00 & $\mathbf{4 . 0 0}$ & $\mathbf{1 0 . 0 0}$ \\
\hline
\end{tabular}

$\chi^{2}=213.97, \mathrm{p}(\chi)=0.000$ 
The Joe-Clayton copula has two parameters $\tau^{\mathrm{U}}$ and $\tau^{\mathrm{L}}$, which are measures of tail dependence. These measures of dependence are defined below.

Definition: if $\left.\lim _{\varepsilon \rightarrow 0} \operatorname{Pr}[\mathrm{U} \leq \varepsilon \mid \mathrm{V} \leq \varepsilon]=\lim _{\varepsilon \rightarrow 0} \operatorname{Pr}|\mathrm{V} \leq \varepsilon| \mathrm{U} \leq \varepsilon\right]=\lim _{\varepsilon \rightarrow 0} \mathrm{C}(\varepsilon, \varepsilon) / \varepsilon=\tau^{\mathrm{L}}$

exists, then the Copula $C$ exhibits lower tail dependence if $\tau^{L} \in(0,1]$ and no lower tail dependence if $\tau^{\mathrm{L}}=0$.

If $\left.\lim _{\delta \rightarrow 1} \operatorname{Pr}[\mathrm{U}>\delta \mid \mathrm{V}>\delta]=\lim _{\delta \rightarrow 1} \operatorname{Pr}|\mathrm{V}>\delta| \mathrm{U}>\delta\right]=\lim _{\delta \rightarrow 1}(1-2 \delta+\mathrm{C}(\delta, \delta)) /(1-\delta)=\tau^{\mathrm{U}}$

exists, then the Copula $\mathrm{C}$ exhibits upper tail dependence if $\tau^{\mathrm{U}} \in(0,1]$ and no upper tail dependence if $\tau^{\mathrm{U}}=0$.

Again, following Patton (op. cit. eq. 15), we take his symmetrised "Joe-Clayton" copula; namely

$$
\mathrm{C}_{\mathrm{SJC}}\left(\mathrm{u}, \mathrm{v} \mid \tau^{\mathrm{U}}, \tau^{\mathrm{L}}\right)=0.5 \cdot\left(\mathrm{C}_{\mathrm{JC}}\left(\mathrm{u}, \mathrm{v} \mid \tau^{\mathrm{U}}, \tau^{\mathrm{L}}\right)+\mathrm{C}_{\mathrm{JC}}\left(1-\mathrm{u}, 1-\mathrm{v} \mid \tau^{\mathrm{L}}, \tau^{\mathrm{U}}\right)+\mathrm{u}+\mathrm{v}-1\right)
$$

Patton argues persuasively that this symmetrisation leads to a framework where symmetric tail-dependence $\left(\tau^{\mathrm{U}}=\tau^{\mathrm{L}}\right)$ is nested within asymmetric tail-dependence, whereas the prior formulae are not symmetric in $\tau^{\mathrm{L}}, \tau^{\mathrm{U}}$. He further argues for timedependent evolution of the dependence parameters; however, it is highly problematic to estimate such models and, thus, the focus here is on a steady-state, rather than a dynamic, copula analysis.

Figure 3 shows the log-likelihood trace for FT All Share and FT Real Estate variance. The converged values with standard errors in parenthesis are $\tau^{\mathrm{U}}=0.3650(0.0907)$ and $\tau^{\mathrm{L}}=0.4258(0.0546)$. It can readily be seen that both the tail parameters are significant. It appears that the lower tail exhibits more dependence than the upper tail, although inspection of the graph suggests a fairly symmetric form. This suggests that the diversification benefits from investing in real estate stocks are weaker when equity markets are underperforming. By implication, this questions the value of real estate companies as defensive stocks in the UK context.

Figure 3: Copula for UK Real Estate Equities and the Stock Market 
Copula Log-likelihood for

FTAS and FTRes

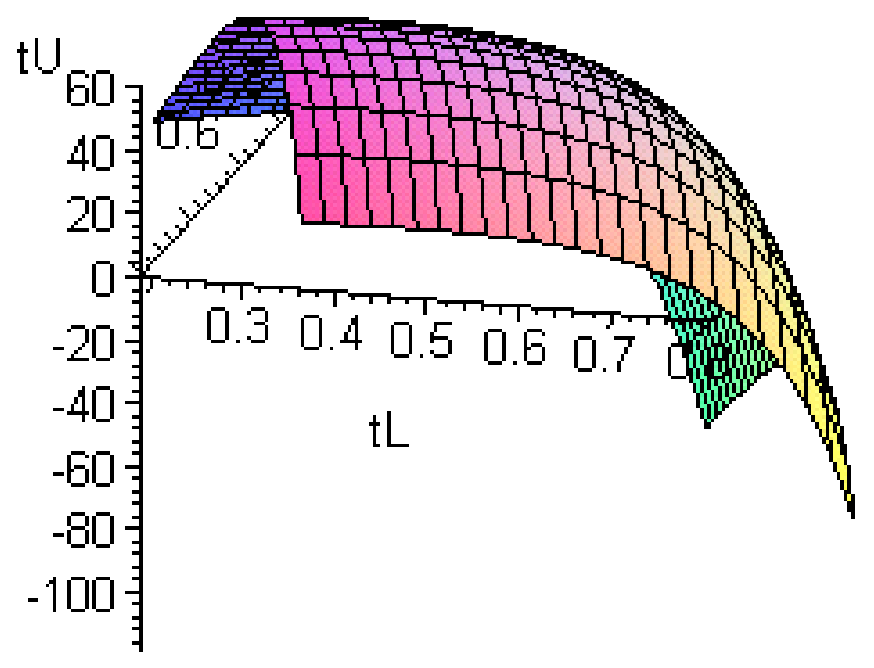

Figure 4 repeats the analysis for the GPR World Real Estate index and the Morgan Stanley World equity values. As before the converged values in both tails are significant: $\tau^{\mathrm{U}}=0.5265(0.0457)$ and $\tau^{\mathrm{L}}=0.4666(0.0558)$. By comparison to the UK market, the tail dependence appears to be more symmetric. 
Figure 4: Copula for Global Real Estate Equities and the Global Equities

\section{Copula Log-likelihood for \\ MSWorld and GPRGlob}

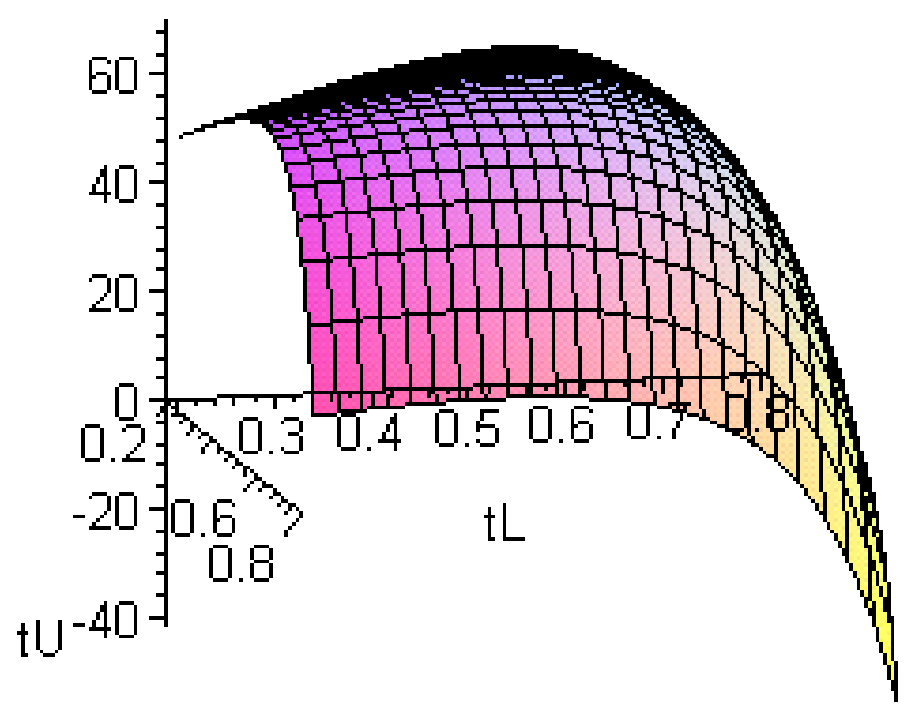

\section{SUMMARY AND CONCLUSIONS}

The results presented here have potentially interesting implications for investors. First, the returns from the direct private market appear to be unrelated to the equity market. While this might appear to point to major diversification benefits, the lack of volatility in the series (even after desmoothing) does not appear to be credible. In any case, the risk facing an individual investor will be greater than that reported, due to illiquidity, the uncertain time to sale and consequent uncertainty as to realisation price. Furthermore, there must be common factors driving returns in the two markets (real interest rates in particular) which suggests that the direct market indices (or, more accurately, the valuations that underlie those indices) are not processing pricesensitive information in a timely manner. 
When comparing the public real estate stocks with equivalent general equity market returns, our results show that both the UK and the GPR global series exhibit tail dependence with their respective equity indices. In the UK case, the tail dependence between the FT Real Estate sector and the FT All Share Index is greater in the lower tail than in the upper tail. This implies that real estate stocks and common equities are more closely locked together when markets are producing poor returns than when markets are generating strong gains. In turn, this suggests that real estate stocks do not demonstrate the defensive qualities that are often claimed for them. That this result holds despite the distorting effect of the dot.com boom bust adds strength to this conclusion. The tail dependence between the GPR Global Property Index and the MS World Index is both stronger and more symmetric than for the UK. Once again, poorly performing equity markets are associated with poorly performing real estate stocks: when diversification is needed most, it is not delivered.

While these are persuasive results, it should be noted that UK property companies are taxable entities, retain earnings and have no restrictions on debt to equity ratios and many of the firms in the GPR index have similar characteristics. As a result, there may be induced volatility and sensitivity to factors that are priced in the equity market than would be the case for a "pure" property investment. Additional analysis focused on tax-neutral public real estate vehicles such as REITs - where the cashflow to investors comes more directly from the performance of the underlying assets held would shed light on the source of the tail-dependence observed. 


\section{Bibliography}

Ang, A. \& Bekaert, G. (2002) International Asset Allocation with Regime Shifts, Review of Financial Studies, 15, 1137-1187.

Ang, A. and Chen, J. (2002) Asymmetric Correlations of Equity Portfolios, Journal of Financial Economics, 63, 443-494.

Bae, K-H., Karolyi, A. and Stulz, R. (2003) A New Approach to Measuring Financial Contagion, Review of Financial Studies, 16, 717-763.

Barkham, R. and Ward, C. (1999) Investor Sentiment and Noise Traders, Journal of Real Estate Research, 18, 291-312.

Bond, S.A. and Hwang, S. (2004) "Liquidity Risk and Real Estate: A Quantitative Approach to Assessing Risk" in C Lizieri (ed) Liquidity in Commercial Property Markets, London: Investment Property Forum.

Bond, S. and Patel, K. (2003) The Conditional Distribution of Real Estate Returns: Relating Time Variation in Higher Moments to Downside Risk Measurement. Journal of Real Estate Finance and Economics, 26, 319-339

Brown, G. and Matysiak, G. (2000) Sticky Valuations, Aggregation Effects and Property Indices, Journal of Real Estate Finance \& Economics, 20, 49-66.

Byrne P. and Lee, S. (1997) Real Estate Portfolio Analysis Under Conditions of NonNormality, Journal of Real Estate Portfolio Management, 3, 37-46.

Campbell, R., Koedijk, K. and Kofman, P. (2002) Increasing Correlation in Bear Markets: A Downside Risk Perspective, Financial Analysts Journal, 58, 87-94.

Clayton, J., Geltner, D. and Hamilton, S. (2001) Smoothing in Commercial Property Valuation: Evidence from Individual Appraisal, Real Estate Economics, 29, 337-360.

Deheuvels, P. (1978) Caractérisation Complète des Lois Extrèmes Multivariées et de la Convergence de Types Extrèmes, Pub. l'Institut de Statist. L'Université de Paris, $23,1-36$.

Deheuvels, P. (1979) La function de Dépendance Empirique et ses Propriétés, Acad. Roy. Belg. Bull. Cl. Sci, 65, 274-292.

Deheuvels, P. (1981) A Non-Parametric Test for Independence Paris: Université de Paris, Institute of Statistics.

Fisher, J., Gatzlaff, D., Geltner, D. and Haurin, D. (2003) Controlling for the Impact of Variable Liquidity on Commercial Real Estate Price Indices, Real Estate Economics, 31, 269-303.

Fisher, J., Geltner, D. and Webb, R.B. (1994) Value Indices of Commercial Real Estate: A Comparison of Index Construction Methods, Journal of Real Estate Finance \& Economics, 9, 137-164. 
Fu, Y. (2003) Estimating the Lagging Error in Real Estate Price Indices, Real Estate Economics, 31, 75-98.

Geltner, D. (1993) Temporal Aggregation in Real Estate Return Indices, Real Estate Economics, 21, 141-166.

Geltner, D., MacGregor, B. and Schwann, G. (2003) Appraisal Smoothing and Price Discovery in Real Estate Markets, Urban Studies, 40, 1047-1064.

Gyourko, J. and Keim, D. (1992) What Does the Stock Market Tell Us About Real Estate Returns? Real Estate Economics, 20, 475-485.

Hamelink, F. and Hoesli, M. (2004) Maximum Drawdown and the Allocation to Real Estate Journal of Property Research 21, 5-29.

Hartmann, P., Straetmans, S. and de Vries, C. (2004) Asset Market Linkages in Crisis Periods, The Review of Economics and Statistics, 86, 313-336.

Joe, H. (1997). Multivariate Models and Dependence Concepts, Monographs on Statistics and Applied Probability, 73, Chapman and Hall, London.

Knight, J., Satchell, S. and Tran, K. (1995) Statistical Modelling of Asymmetric Risk in Asset Returns, Applied Mathematical Finance, 1, 155-172.

Lai, T. and Wang, K. (1998) Appraisal Smoothing: The Other Side of the Story Real Estate Economics, 26, 511-536.

Ling, D. and Naranjo, A. (1999) The Integration of Commercial Real Estate Markets and the Stock Market, Real Estate Economics, 27, 483-516.

Liu, C., Hartzell, D., Greig, W. And Grissom, T. (1990) The Integration of the Real Estate Market and the Stock Market, Journal of Real Estate Finance \& Economics, 3, 261-282.

Lizieri, C. and Ward, C. (2000) The Distribution of Real Estate Returns, in: J Knight \& S Satchell (eds) Return Distributions in Finance Butterworth-Heinemann, Oxford; ISBN: 0750647515, pp 47-74

Longin, F. and Solnik, B. (2001) Extreme Correlation of International Equity Markets, Journal of Finance, 56, 649-676.

Maitland-Smith, J. and Brooks, C. (1999) Threshold Autoregressive and Markov Switching Models: An Application to Commercial Real Estate, Journal of Property Research, 16, 1-20.

McAllister, P., Baum, A., Crosby, N., Gallimore, P. and Gray, A. (2003) Appraisal behaviour and appraisal smoothing : some qualitative and quantitative evidence. Journal of Property Research, 20, 261-280. 
Nelsen, R. (1999) An Introduction to Copulas, New York: Springer-Verlag

Okunev, J. and Wilson, P. (1997) Using Non-Linear Tests to Examine Integration Between Real Estate and Stock Markets, Real Estate Economics, 25, 487-503.

Patton, A. (2005). Modelling Asymmetric Exchange Rate Dependence. Mimeo, London School of Economics

Silvapulle, P. and Granger, C. (2001) Large Returns, Conditional Correlation and Portfolio Diversification: A Value at Risk Approach, Quantitative Finance, 1, 542551.

Young, M. \& Graff, R. (1995) Real Estate is Not Normal, Journal of Real Estate Finance \& Economics, 10, 223-259. 


\section{Appendix A: Results For The Marginal Distributions}

All series are log differenced

FT All Share Index Series

Form: GARCH(2,4)-t

\begin{tabular}{|c|c|c|c|c|}
\hline & Coefficient & Std. Error & z-Statistic & Prob. \\
\hline $\mathrm{C}$ & 0.012249 & 0.002311 & 5.300316 & 0 \\
\hline \multicolumn{5}{|c|}{ Variance Equation } \\
\hline $\mathrm{C}$ & $2.46 \mathrm{E}-06$ & $9.59 \mathrm{E}-06$ & 0.256092 & 0.7979 \\
\hline $\operatorname{RESID}(-1)^{\wedge} 2$ & 0.195285 & 0.008881 & 21.98862 & 0 \\
\hline $\operatorname{RESID}(-2)^{\wedge} 2$ & -0.204823 & 0.006911 & -29.63672 & 0 \\
\hline GARCH(-1) & 1.472189 & 0.068294 & 21.55654 & 0 \\
\hline GARCH(-2) & -0.42986 & 0.009734 & -44.15882 & 0 \\
\hline GARCH(-3) & -0.159392 & 0.062208 & -2.562251 & 0.0104 \\
\hline GARCH(-4) & 0.123377 & 0.008562 & 14.4106 & 0 \\
\hline T-DIST. DOF & 5.390647 & 2.095523 & 2.572459 & 0.0101 \\
\hline
\end{tabular}


FT Real Estate Series

Form: AR(1)-GARCH(1,2)

\begin{tabular}{|ccccc|}
\hline & Coefficient & Std. Error & z-Statistic & Prob. \\
& & & & \\
\hline \hline C & 0.005842 & 0.002339 & 2.497749 & 0.0125 \\
DLFTRES(-1) & 0.15578 & 0.039244 & 3.9695 & 0.0001 \\
& & & & \\
\hline \hline \multicolumn{5}{c}{ Variance Equation } \\
C & & & \\
RESID(-1)^2 & -0.041646 & 0.010171 & -4.09466 & 0 \\
GARCH(-1) & 0.477248 & 0.017041 & 28.00611 & 0 \\
GARCH(-2) & 0.554219 & 0.000661 & 838.2014 & 0 \\
\hline \hline
\end{tabular}

MS World Equity Markets Series

Form: GARCH( $(0,2)$-t

\begin{tabular}{|c|c|c|c|c|}
\hline & Coefficient & Std. Error & z-Statistic & Prob. \\
\hline $\mathrm{C}$ & 0.008542 & 0.002534 & 3.371516 & 0.0007 \\
\hline \multicolumn{5}{|c|}{ Variance Equation } \\
\hline $\mathrm{C}$ & 0.000544 & $9.76 \mathrm{E}-05$ & 5.580919 & 0 \\
\hline GARCH(-1) & 1.619564 & 0.092074 & 17.58982 & 0 \\
\hline GARCH(-2) & -0.896871 & 0.078436 & -11.43443 & 0 \\
\hline T-DIST. DOF & 7.173943 & 3.840293 & 1.868072 & 0.0618 \\
\hline
\end{tabular}




\section{GPR Global Property Index Series}

Form: $\operatorname{GARCH}(1,1)$

\begin{tabular}{|c|c|c|c|c|}
\hline & Coefficient & Std. Error & z-Statistic & Prob. \\
\hline $\mathrm{C}$ & 0.006995 & 0.002954 & 2.367611 & 0.0179 \\
\hline \multicolumn{5}{|c|}{ Variance Equation } \\
\hline $\mathrm{C}$ & 4.62E-05 & $1.29 \mathrm{E}-05$ & 3.585340 & 0.0003 \\
\hline $\operatorname{RESID}(-1)^{\wedge} 2$ & -0.037726 & 0.017425 & -2.165082 & 0.0304 \\
\hline GARCH(-2) & 1.009198 & 0.014653 & 68.87369 & 0.0000 \\
\hline
\end{tabular}

